\title{
Reverse transcription-PCR assay for the rapid detection of viable Vibrio cholerae from fresh and processed shrimp
}

\author{
G. JEYASEKARAN*, M. PALANIKUMAR, A. VARATHARAJAKUMAR \\ AND R. JEYA SHAKILA \\ Fish Quality Assurance and Management Department, Fisheries College and Research Institute \\ Tamil Nadu Fisheries University, Thoothukudi - 628 008, Tamil Nadu, India \\ e-mail: jeyasekarang@gmail.com
}

\begin{abstract}
Viable Vibrio cholerae in seafood was rapidly detected by the Reverse transcription-PCR (RT-PCR) assay developed by targeting mRNA ctxA gene without any pre-enrichment. The PCR product size of the selected gene was $308 \mathrm{bp}$, which aided in the identification of $V$. cholerae. This RT-PCR assay was rapid, as it detected $V$. cholerae from fresh shrimp tissue within 5 min on bioinoculation when the cell count was 1,000,000 cells. The pathogen was detected in $5 \mathrm{~h}$ when the load was $110 \mathrm{cells}$. The assay even detected the pathogen in shrimp that has been cooked for $10 \mathrm{~min}$, frozen for 30 days and even in dried shrimp. Other food-borne pathogens like Salmonella, Staphylococcus aureus and Listeria monocytogenes were not detected by this assay. The developed RT-PCR assay is thus specific and rapid in detecting the viable Vibrio cholerae in seafood without any pre-enrichment.
\end{abstract}

Keywords: RT-PCR, Seafood, Shrimp, Vibrio cholerae

\section{Introduction}

The epidemic cholera, caused by Vibrio cholerae, is the watery diarrhea resulting in dehydration and sometimes death. The important reservoir for $V$. cholerae is the coastal waters and it is normally transmitted to human beings through contaminated water and seafood (Colwell et al., 1981). Two important serogroups $\mathrm{O} 1$ and $\mathrm{O} 139$ of $V$. cholerae among 200 known serogroups are associated with epidemic cholera (Cholera Working Group, 1993). The Inaba, Ogawa and Hikojima are the three serotypes under the serogroup $\mathrm{O} 1$ and the serotype is divided into two biotypes viz., classical and El Tor (Kaper et al., 1995). The non-O1 and non-O139 serogroups of $V$. cholerae are not associated with epidemics, but with the occasional outbreaks of cholera-like diseases. Though the pathogenesis of cholera is complex, the major virulence factor of $V$. cholerae is the cholera toxin (CT) encoded by the ctxA gene (Kaper et al., 1995). CT causes increased secretion of electrolytes and water into the lumen of the intestine. The ctxA gene located in genome of the CTX filamentous prophage (Lee et al., 1999) is responsible for massive and watery diarrhea of cholera.

The culture-based method for the detection of $V$. cholerae in fishery products is laborious, time consuming and often not specific. Though few alternative analytical strategies are proposed, PCR based method is found to be the highly specific molecular diagnostic tool (Wang et al., 1997; Jeyasekaran et al., 2011a). The sensitivity of the PCR based technique may be reduced dramatically when applied to complex biological samples (Lantz et al., 2000), even though this can be extremely effective on pure solutions of nucleic acids. However, PCR does not provide information related to cell viability, as the DNA molecules from live and dead cells cannot be distinguished by the PCR (Josephson et al., 1993; Masters et al., 1994). A pre-enrichment step is essentially performed to allow viable cells to grow and multiply that improve the discrimination power of PCR (Wang et al., 1997). Pre-enrichment takes 6-48 h to complete, which is a major drawback in PCR (Call et al., 2001). Since only viable bacteria produce toxins that cause human disease, the distinction between viable and dead bacteria is important (Law, 2000).

It would be of enormous significance for food, industrial, environmental and medical applications, if a nucleic acid-based method is developed and applied directly to samples without pre-enrichment indicating the viability of microbes. A method for the detection of specific mRNA in individual bacterial cells was described by Tolkar-Neilsen et al. (1997). Most mRNA in living bacterial cells has a half-life of only a few minutes (Alifano et al., 1994). Hence, the detection of mRNA shall be a good indicator of viability of cells (Hill, 1996; Sheridan et al., 1998). Investigations on the relationship between microbial mRNA and viability in $V$. cholerae and Listeria monocytogenes using RT-PCR were specifically studied by Bej et al. (1996) and Klein and 
Juneja (1997). The present study was undertaken to detect viable $V$. cholerae from shrimp tissue using mRNA based RT-PCR assay without pre-enrichment.

\section{Materials and methods}

\section{Type cultures of bacteria and other materials}

Vibrio cholerae type cultures used are Vibrio cholerae O139 (SG 24), V. cholerae El Tor (N 16961) and $V$. cholerae Classical (V 154). Type cultures of other bacterial pathogens like Salmonella enterica serovar Typhi (ATCC 122235), S. enterica serovar Enteritidis (ATCC 13065), Staphylococcus aureus (ATCC 12598), Escherichia coli (ATCC 9637), Aeromonas hydrophila (ATCC 1457) and Listeria monocytogenes (ATCC 12232) were used to check specificity of the assay. Trypticase soy broth (TSB) was used for growing type cultures and incubation was done at $37^{\circ} \mathrm{C}$ for $18 \mathrm{~h}$ prior to the extraction of total RNA. Media and ingredients supplied by Hi-Media Laboratories Pvt. Ltd, Mumbai, India were used in the experiment. Nuclease free water obtained from molecular grade water purification system (Sartorius Stedim Biotech, Gottingen, Germany) was used for development of assay.

Extraction of total RNA from bacterial type cultures and shrimp tissue

The total RNA was extracted from type cultures using a commercial RNA extraction kit [Real Biotech Corporation (RBC), Ohio, USA]. One milliliter of broth culture $(18 \mathrm{~h}$ old) was used to obtain purified $50 \mu$ of RNA following the manufacture's protocol. In the case of shrimp tissue, about $30 \mathrm{mg}$ tissue homogenate was used to obtain $50 \mu \mathrm{l}$ of RNA as per the protocol of the manufacturer. The RNA was treated with DNase I (Fermentas, Whatman, USA) for removing any contaminating DNA. The DNase treated RNA was immediately frozen at $-70^{\circ} \mathrm{C}$ until used as a template for cDNA synthesis. Biophotometer (Eppendorf AG, Germany) was used to measure the concentration and purity of the extracted RNA.

\section{cDNA synthesis}

The RNA was converted into cDNA by performing reverse transcription as per the standard protocol (Fermentas, Waltham, U.S.A). Each reaction tube contained extracted RNA (1-5 $\mu \mathrm{g})$, random hexamer primer $\left(0.2 \mu \mathrm{g} \mathrm{ul} l^{-1}\right)$ and the volume was made up to $11 \mu \mathrm{l}$ with nuclease free water. After incubation at $65^{\circ} \mathrm{C}$ for $5 \mathrm{~min}$, the tubes were placed on ice and the components provided in the kit viz., $5 \mathrm{X}$ reaction

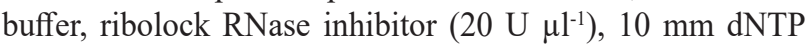

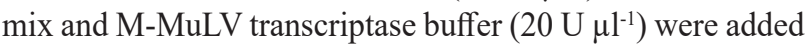
to the final volume of $20 \mu \mathrm{l}$. The tubes were again incubated at $37^{\circ} \mathrm{C}$ for $60 \mathrm{~min}$ and then heated at $70^{\circ} \mathrm{C}$ for $5 \mathrm{~min}$ for terminating the reaction. The cDNA obtained was stored at $-20^{\circ} \mathrm{C}$ until used as template in PCR.
Primers

Forward and reverse primer pair (ctx $A$ F 5' ACA GAG TGA GTA CTT TGA CC 3' and $c t x A$ R 5' ATA CCA TCC ATA TAT TTG GGA G 3') used was based on mRNA of $c t x A$ gene (amplified a product size of $308 \mathrm{bp}$ ) for Vibrio cholerae (Hoshino et al., 1998). The primer (desalted) supplied by Ocimum Biosolutions Inc., Indianapolis, USA was used.

Reverse transcription-Polymerase chain reaction (RT-PCR)

A gradient master cycler (Eppendorf AG, Hamburg, Germany) was used for performing the RT-PCR. A biosafety cabinet Type II (Clean Air Systems, Chennai, India) was used for handling all PCR mixtures. The amplification was performed in $25 \mu \mathrm{l}$ of reaction mixture containing $1 \mu \mathrm{l}$ of template cDNA of $V$. cholerae, 10X PCR buffer $100 \mathrm{~mm}$ Tris, $\mathrm{pH} 9.0,500 \mathrm{~mm} \mathrm{KCl}, 15 \mathrm{~mm} \mathrm{MgCl}$ and $0.1 \%$ gelatin, 100 $\mathrm{mm}$ of each dNTP, 30 pmols of each primer and $1.25 \mathrm{U}$ of Taq DNA polymerase. The optimised RT-PCR conditions were initial denaturation at $94^{\circ} \mathrm{C}$ for $3 \mathrm{~min}$, followed by denaturation at $94^{\circ} \mathrm{C}$ for $60 \mathrm{~s}$; annealing at $55^{\circ} \mathrm{C}$ for $60 \mathrm{~s}$; extension at $72^{\circ} \mathrm{C}$ for $90 \mathrm{~s}$, and final extension at $72^{\circ} \mathrm{C}$ for $3 \mathrm{~min}$. The resulting RT-PCR product was run on $2 \%$ agarose gel containing ethidium bromide $\left(5 \mathrm{mg} \mathrm{ml}^{-1}\right)$ in Tris acetate EDTA buffer (TAE, pH 8.5) along with 100 bp DNA ladder.

\section{Specificity of RT-PCR assay}

The specificity of the developed RT-PCR for Vibrio cholerae was tested by performing the RT-PCR assay with other food-borne bacterial pathogens such as Salmonella enterica serovar Typhi (ATCC 122235), S. enterica serovar Enteritidis (ATCC 13065), Staphylococcus aureus (ATCC 12598), Escherichia coli (ATCC 9637), Aeromonas hydrophila (ATCC 1457) and Listeria monocytogenes (ATCC 12232).

\section{Sensitivity of RT-PCR assay in shrimp tissue}

Bio-inoculation studies of type culture of Vibrio cholerae in shrimp tissue was performed for testing the sensitivity of the developed RT-PCR assay. A tissue homogeniser was used for homogenising the shrimp tissue. Approximately $1 \mathrm{~g}$ of tissue homogenate was taken in sterile eppendorf tubes. Overnight grown type culture $\left(1.00 \times 10^{7}\right.$ CFU ml ${ }^{-1}$ ) of $V$. cholerae $\mathrm{O} 139$ (SG 24) was serially diluted up to $10^{-9}$ and an aliquot of $50 \mu 1$ was inoculated into the tissue. The bacterial count in each serial dilution was ascertained by plating onto thiosulphate citrate bile salt sucrose (TCBS) agar plates and incubated at $37^{\circ} \mathrm{C}$ for $48 \mathrm{~h}$ (Shikongo-Nambabi et al., 2012). The bio-inoculated tissue homogenates were incubated for 5, 10, $20 \mathrm{~min}$ (for $10^{-1}$ and $10^{-2}$ dilutions) and $3,4,5 \mathrm{~h}$ (for $10^{-7}, 10^{-8}$ and $10^{-9}$ dilutions) at $37^{\circ} \mathrm{C}$. Different dilutions of bio-inoculated samples were prepared for various inoculation periods to get a range of bacterial cells from $10^{1}$ to $10^{6}$ as per earlier reports of Sheridan et al. (1998). 
Uninoculated tissue homogenate was used as a control. After incubation, $30 \mathrm{mg}$ of tissue homogenate was used for the extraction of total RNA, and for performing RT-PCR assay as described earlier. The experiment was independently repeated thrice for concurrent results.

Validation of RT-PCR assay

The shrimp tissue samples were divided into 4 lots to validate the developed RT-PCR assay in detecting viable $V$. cholerae from the shrimp samples that had been subjected to different processing treatments viz., freezing, cooking and drying. The first lot was the uninoculated shrimp tissue and designated as 'Control or $\mathrm{C}$. The remaining three lots were subjected to different processing treatments. About $30 \mathrm{~g}$ of tissue was divided into three lots of $10 \mathrm{~g}$ and $1 \mathrm{ml}$ each of tenfold serial dilution $\left(10^{-1}\right.$ and $10^{-2}$, equivalent to $10^{6}$ and $10^{5}$ cells, respectively) of an overnight grown culture of V. cholerae $\mathrm{O} 139$ (SG 24) containing $1 \times 10^{7} \mathrm{CFU} \mathrm{ml}^{-1}$, was inoculated into $10 \mathrm{~g}$ of shrimp tissue. All the experiments were carried out in triplicates. The second lot was subjected to slow freezing (SF) in a deep freezer at $-20^{\circ} \mathrm{C}$ as per the protocol given by Jeyasekaran et al. (2002) and subdivided into two lots. They were designated as SF15 and SF30 with respect to the storage periods i.e. 15 days and 30 days respectively. The third lot was cooked at $100^{\circ} \mathrm{C}$ in boiling water for 5,10 and $20 \mathrm{~min}$ and designated as C5, C10 and C20 respectively. The fourth lot was dried under direct sunlight for a period of 15 days and subdivided into two sub-lots. Samples were taken for analysis after storage of 15 and 30 days and designated as D15 and D30, respectively.

\section{Results and discussion}

Reverse transcription-Polymerase chain reaction (RT-PCR)

RT-PCR performed for the $c t x A$ gene yielded a product of $308 \mathrm{bp}$ only in case of $V$. cholerae (Fig. 1). The selected target gene and also the presence of inhibitors in the food matrix that may prevent sufficient extraction of template for amplification or may inhibit the amplification process are the important factors affecting the detection of pathogenic microorganisms in food by RT-PCR. Bickely et al. (1996) have reported the effect of inhibitors in a variety of products, including blood, faeces and food. However, many of the obstacles can be overcome by enrichment procedures that increase the cell numbers (McIngvale et al., 2002).

Klein and Juneja (1997) developed a reverse transcription-PCR (RT-PCR) for reliably detecting viable L. monocytogenes by targeting mRNA of iap, hlyA and prfA genes. Yaron and Matthews (2002) detected viable E. coli using RT-PCR assay by targeting $r f b E$, $f l i C$ and $s t x 1$ mRNA genes. The detection of viable Salmonella by targeting invA mRNA from the artificial contaminated spinach, tomatoes and pepper without any false positive results from dead cells

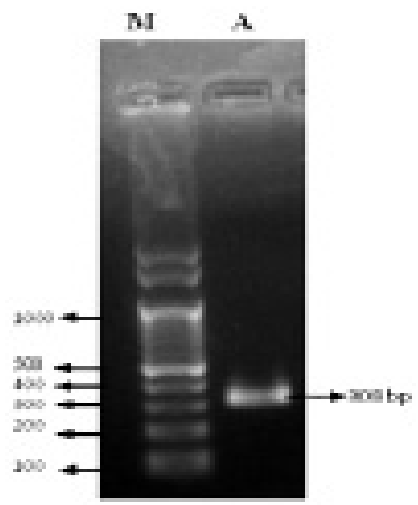

Fig. 1. RT-PCR assay for Vibrio cholerae. Lane A - ctxA; Lane M - 100bp DNA ladder

was reported by Gonzalez-Escalona et al. (2009). All the above studies employed the pre-enrichment procedure. But, in the present study, viable $V$. cholerae from shrimp without pre-enrichment targeting mRNA ctx $A$ gene was detected by the RT-PCR assay developed. Since the present assay did not involve any pre-enrichment, it was rapid when compared to the RT-PCR assays developed by earlier workers.

\section{Specificity and sensitivity of RT-PCR assay in shrimp tissue}

The assay showed $100 \%$ specificity of the selected gene, as it was specific only for Vibrio cholerae and did not get amplified in case of bacterial pathogens like Salmonella sp., L. monocytogenes, S. aureus and E. coli (Table 1 and Fig. 2).

Morin et al. (2004) also reported that the presence of other bacteria did not interfere in RT-PCR detection of the bacterial pathogens like Salmonella and E. coli in clinical isolates. RT-PCR assay showed amplification of $V$. cholerae specific gene in 5, 10 and 20 min incubated shrimp tissue in the dilutions of $10^{-1}$ and $10^{-2}$ which was equivalent to above $10^{6}$ cells (Fig. 3).

There was no amplification of $V$. cholerae specific gene in the 3 and $4 \mathrm{~h}$ incubated shrimp tissue in the dilutions of $10^{-7}, 10^{-8}$ and $10^{-9}$ equivalent to $20,67,11,36,2$ and 6 cells,

Table 1. Bacterial strains tested with the presence/absence of tested gene

\begin{tabular}{ll}
\hline Bacterial strains & ctxA gene \\
\hline Vibrio cholerae O139 (SG 24) & + \\
Vibrio cholerae El Tor (N 16961) & + \\
Vibrio cholerae Classical (V 154) & + \\
Salmonella enterica serovar Typhi (ATCC & - \\
122235) & \\
S. enterica serovar Enteritidis (ATCC 13065) & - \\
Staphylococcus aureus (ATCC 12598) & - \\
Escherichia coli (ATCC 9637) & - \\
Aeromonas hydrophila (ATCC 1457) & - \\
Listeria monocytogenes (ATCC 12232) & - \\
\hline
\end{tabular}




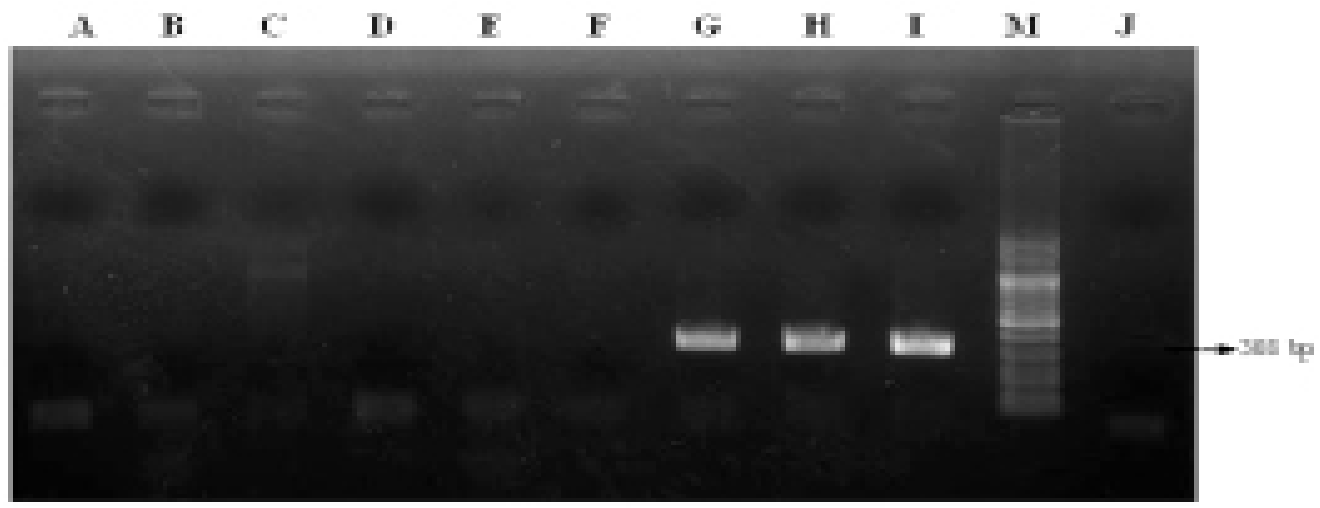

Fig. 2. Specificity of RT-PCR assay developed for Vibrio cholerae.

Lane A - Salmonella enterica serovar Typhi (ATCC 122235); Lane B - S. enterica serovar Enteritidis (ATCC 13065); Lane C - Staphylococcus aureus (ATCC 12598); Lane D - Escherichia coli (ATCC 9637); Lane E - Aeromonas hydrophila (ATCC 1457); Lane F - Listeria monocytogenes (ATCC 12232); Lane G - Vibrio cholerae O139 (SG 24), Lane H - V. cholerae El Tor (N 16961), Lane I - V. cholerae Classical (V 154); Lane M - 100 bp DNA ladder; Lane J - Control (Uninoculated)

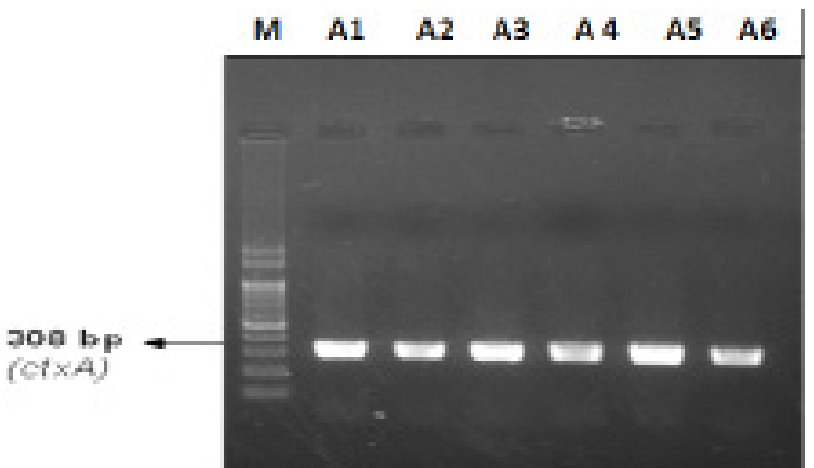

Fig. 3. Sensitivity of RT-PCR assay developed for Vibrio cholerae targeting mRNA $c t x A$ gene

Lanes A1, A3, A5 - $10^{-1}$ diluted sample incubated for 5, 10 and $20 \mathrm{~min}$; Lanes A2, A4, A6 - 10-2 diluted sample incubated for 5, 10 and $20 \mathrm{~min}$; Lane M - $100 \mathrm{bp}$ DNA ladder

respectively and the amplification was observed in $5 \mathrm{~h}$ incubated shrimp tissue in the dilutions of $10^{-7}$ and $10^{-8}$ equivalent to 143 and 110 cells. Though 91 cells were present in $10^{-9}$ diluted shrimp tissue in $5 \mathrm{~h}$, no amplification of specific gene of $V$. cholerae was found (Fig. 4). Theron et al. (2000) evaluated the performance of a semi-nested ctx $A B$ gene specific PCR for the detection of pathogenic $V$. cholerae in environmental water and drinking water sources within $10 \mathrm{~h}$. The sensitivity obtained in this work for RT- PCR assay is much better when compared to the earlier works reported on bacterial pathogens (Klein and Juneja, 1997; Yaron and Matthews, 2002). Klein and Juneja (1997) found that $10^{4}$ cells of $L$. monocytogenes is required for its detection targeting mRNA of $h l y A$ gene by RT-PCR assay. Yaron and Matthews (2002) also observed that $10^{7}$ cells of $E$. coli is needed for its detection targeting mRNA of $f i C$ gene by RT-PCR assay. Since the estimated infective dose of

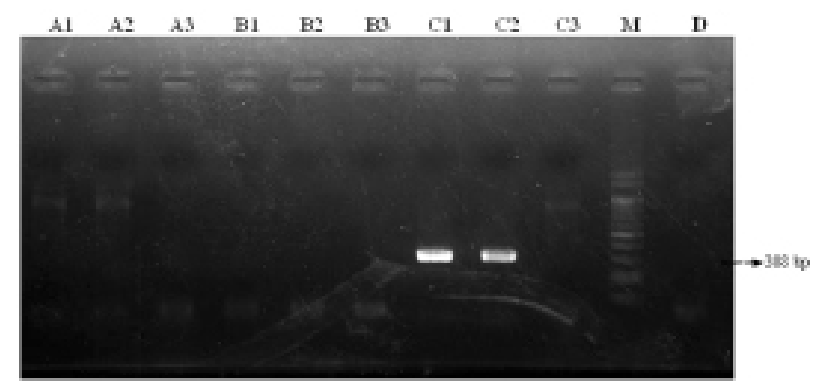

Fig. 4. Sensitivity of RT-PCR assay developed for Vibrio cholerae targeting mRNA ctx $A$ gene

Lanes A1, A2 and A3 - 10-7, $10^{-8}$ and $10^{-9}$ diluted samples incubated for $3 \mathrm{~h}$; Lanes B1, B2 and B3 $-10^{-7}, 10^{-8}$ and $10^{-9}$ diluted samples incubated for $4 \mathrm{~h}$; Lanes $\mathrm{C} 1, \mathrm{C} 2$ and $\mathrm{C} 3-10^{-7}, 10^{-8}$ and $10^{-9}$ diluted samples incubated for $5 \mathrm{~h}$; Lane M - 100 bp DNA laddder; Lane D - Control (Uninoculated)

V. cholerae is about $10^{6}$ cells (FDA, 2012), the detection limit of the developed RT-PCR assay is sufficient for screening the pathogen below the infective dose.

\section{Validation of RT-PCR assay}

The stability of mRNA based RT-PCR assay for the detection of viable $V$. cholerae was studied by carrying out bio-inoculation experiments. The RT-PCR assay detected viable $V$. cholerae in frozen shrimp tissue even on the $30^{\text {th }}$ day of storage (Fig. 5).

The RT-PCR assay developed in the present study detected viable $V$. cholerae even after cooking for $20 \mathrm{~min}$ (Fig. 6). V. cholerae was also detected by RT-PCR assay even on the $30^{\text {th }}$ day in dried shrimp tissue (Fig. 7). Sheridan et al. (1998) have also reported that mRNA was detected in heat $\left(100^{\circ} \mathrm{C}\right.$ for $\left.5 \mathrm{~min}\right)$ treated cells of $E$. coli even after incubation at room temperature for $16 \mathrm{~h}$. They have also observed 


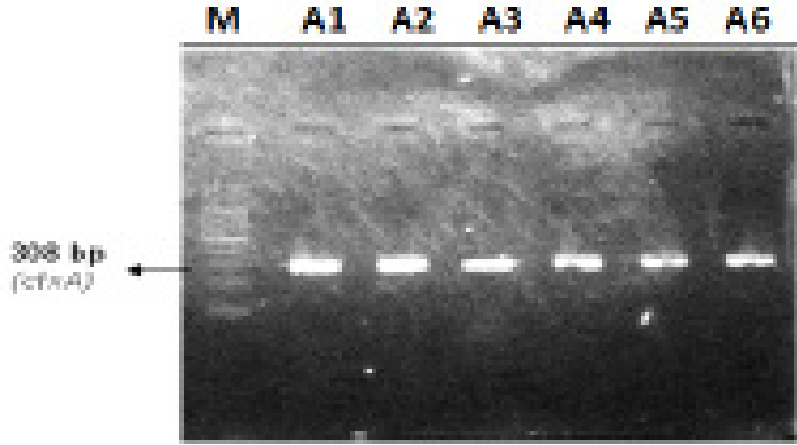

Fig. 5. Validation of RT-PCR assay for the detection of viable Vibrio cholerae using specific mRNA ctxA gene in shrimp tissue on frozen storage

Lanes A1, A3, A5 - $10^{-1}$ diluted sample frozen stored for 1, 15 and 30 days; Lanes A2, A4, A6 - 10-2 diluted sample frozen stored for 1, 15 and 30 days; Lane M - 100 bp DNA ladder

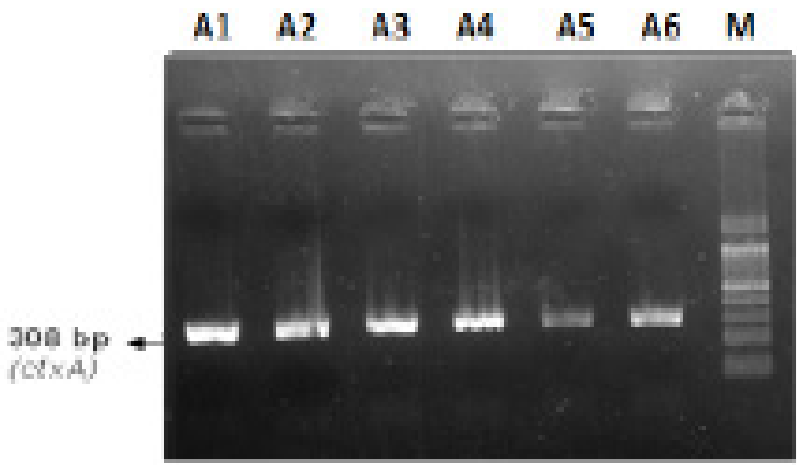

Fig. 6. Validation of RT-PCR assay for the detection of viable Vibrio cholerae using specific mRNA ctxA gene in cooked shrimp tissue

Lanes A1, A3, A5 - 10-1 diluted sample cooked for 5, 10 and $20 \mathrm{~min}$; Lanes A2, A4, A6 - 10-2 diluted sample cooked for 5, 10, 20 min; Lane M - 100 bp DNA ladder

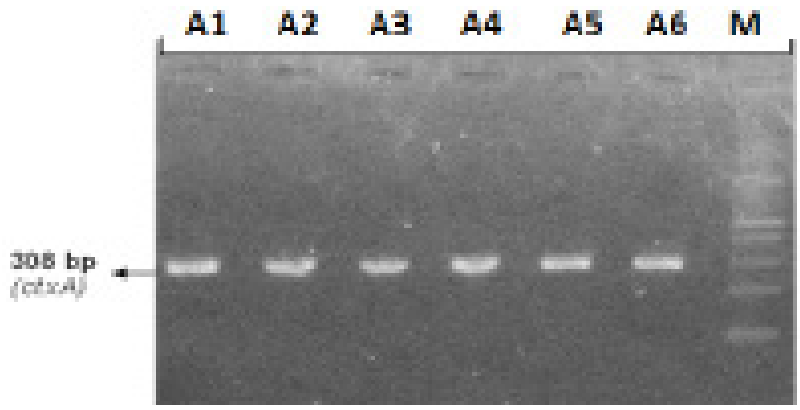

Fig. 7. Validation of RT-PCR assay for the detection of viable Vibrio cholerae using specific mRNA ctxA gene (308 bp) in shrimp tissue on drying

Lanes A1, A3, A5 - $10^{-1}$ diluted sample dried and stored for 1, 15 and 30 days; Lanes A2, A4, A6 - $10^{-2}$ diluted sample dried and stored for 1, 15 and 30 min days. Lane M - 100 bp DNA ladder that detection of mRNA after heat treatment varied with the stability of different mRNA sequences targeted by the oligonucleotide primers designed as well as with the relative abundance of each mRNA type in a given cell.

Expansion of the international food trade resulted in the emergence of members of vibrios as the most important emerging food and waterborne pathogens both in developing and developed countries (Jeyasekaran et al., 2011b). These human pathogenic vibrios are transmitted either by direct contact or indirectly through contaminated seafood products (Kumar, 2008; Jeyasekaran et al., 2011b). Since some of the environmental strains are lacking the genes, the identification of cholera toxin is important (Rivera et al., 2001). Development of a suitable methodology for rapid, viable, sensitive and specific monitoring of these bacteria in food products is always necessary and attract more interest, as it would greatly facilitate the sanitary control of food products and lower the incidence of associated food-borne infections. It is well known that mRNA detection by RT-PCR is the most promising technique for investigating the viability of bacteria (Call et al., 2001). RT-PCR for the detection of Vibrio spp. from clinical stool samples were attempted by Call et al. (2001) and Morin et al. (2004). Detection of ctx A mRNA by RT-PCR in the present study indicated that the loss of viability was well correlated with the loss of the RT-PCR signal in the cooked samples.

It can be concluded that the reverse transcriptionPCR (RT-PCR) assay developed in this study was rapid, reliable, specific and sensitive in the detection of viable $V$. cholerae in seafood targeting mRNA of $c t x A$ gene without pre-enrichment. This RT-PCR assay detected only the viable $V$. cholerae but not the other pathogens (Salmonella, Escherichia coli, Staphylococcus aureus, Aeromonas hydrophila and Listeria monocytogenes) tested.

\section{Acknowledgements}

The financial assistance extended by the Department of Biotechnology, Govt. of India, New Delhi for conducting this research work is gratefully acknowledged. Authors wish to thank the Vice Chancellor, Tamil Nadu Fisheries University, Nagapattinam, India for having provided necessary support for carrying out this work.

\section{References}

Alifano, P., Rivellini, F., Piscitelli, C., Arraiano, C. M., Bruni, C. B. and Carlomagno, M. S. 1994. Ribonuclease E provides substrates for ribonuclease P-dependent processing of a polycistronic mRNA. Genes Develop., 8: 3021-3031.

Bej, A. K., Ng, W. Y., Morgan, S., Jones, D. and Mahbubani, M. H. 1996. Detection of viable Vibrio cholerae by reversetranscriptase polymerase chain reaction (RT-PCR). Mol. Biotechnol., 5:1-10. 
Bickley, J., Short, J. K., McDowell, D. G. and Parkes, H. C. 1996. Polymerase chain reaction (PCR) detection of Listeria monocytogenes in diluted milk and reversal of PCR inhibition caused by calcium ions. Lett. Appl. Microbiol., 22: 153-158.

Call, D. R., Brockman, F. J. and Chandler, D. P. 2001. Detecting and genotyping Escherichia coli O157, $\mathrm{H} 7$ using multiplexed PCR and nucleic acid microarrays. Int. J. Food Microbiol., 67: 71-80

Cholera Working Group 1993. Large epidemic of cholera-like disease in Bangladesh caused by Vibrio cholerae 0139 synonym Bengal. Lancet, 342: 387-390.

Colwell, R. R., Seidler, R. J., Kaper, J., Joseph, S. W., Garges, S., Lockman, H., Maneval, D., Bradford, H., Roberts, N., Remmers, E., Huq, I. and Huq, A. 1981. Occurrence of Vibrio cholerae serotype $\mathrm{O} 1$ in Maryland and Louisiana estuaries. Appl. Environ. Microbiol., 41: 555-558.

FDA 2012. Bad bug book, food borne pathogenic microorganisms and natural toxins. $2^{\text {nd }}$ edn. Food and Drug Administration, USA.

Gonzalez-Escalona, N., Hammack, T. S., Russell, M., Jacobson, A. P., De Jesus, A. J., Brown, E. W. and Lampel, K. A. 2009. Detection of live Salmonella sp. cells in produce by a TaqMan-based quantitative reverse transcriptase real-time PCR targeting invA mRNA. Appl. Environ. Microbiol., 75: 3714-3720.

Hill, W. E. 1996. The polymerase chain reaction, applications for the detection of foodborne pathogens. Crit. Rev. Food Sci. Nutr., 36: $123-173$.

Hoshino, K., Yamasaki, S., Mukhopadhyay, A. K., Chakraborty, S., Basu, A., Bhattacharya, S. K., Nair, G. B., Shimada, T. and Takeda, Y. 1998. Development and evaluation of a multiplex PCR assay for rapid detection of toxigenic Vibrio cholerae $\mathrm{O} 1$ and O139. FEMS Immunol. Med. Microbiol., 20: 201-207.

Jeyasekaran, G., Rathnakumar, K. and Velayutham, P. 2002. Freezing of fish and shellfishes. Tamil Nadu Veterinary and Animal Sciences University, Chennai, p. 119.

Jeyasekaran, G., Thirumalairaj, K., Jeyashakila, R., Jemilathangarani, A. and Sukumar, D. 2011a. Detection of Salmonella enterica serovars in shrimps in eight hours by multiplex PCR assay. Ann. Microbiol., 62: 225-231.

Jeyasekaran, G., Thirumalairaj, K., Jeyashakila, R., Jemilathangarani, A. and Sukumar, D. 2011b. Multiplex polymerase chain reaction-based assay for the specific detection of toxinproducing Vibrio cholerae in fish and fishery products. Appl. Microbiol. Biotechnol., 90: 1111-1118.
Josephson, K. L., Gerba, C. P. and Pepper, I. L. 1993. Polymerase chain reaction detection of nonviable bacterial pathogens. Appl. Environ. Microbiol., 59: 3513-3515.

Kaper, J. B., Morris Jr, J. G. and Levine, M. M. 1995. Cholera. Clin. Microbiol. Rev., 8: 48-86.

Klein, P. G. and Juneja, V. K. 1997. Sensitive detection of viable Listeria monocytogenes by reverse-transcriptase PCR. Appl. Environ. Microbiol., 63: 4441-4448.

Kumar, R., Surendran, P. K. and Thampuran, N. 2008. An eight hour PCR - based technique for detection of Salmonella serovars in seafood. World J. Microbiol. Biotechnol., 24: 627-631.

Lantz, P. G., Abu Al-Soud, W., Knutsson, R., Hahn-Hagerdal, B. and Radstrom, P. 2000. Biotechnical use of the polymerase chain reaction for microbiological analysis of biological samples. Biotechnol. Ann. Rev., 5: 87-130.

Law, D. 2000. Virulence factors of Escherichia coli 0157 and other Shiga toxin - producing E. coli. J. Appl. Microbiol., 88: 729-745.

Lee, S. H., Hava, D. L., Waldor, M. K. and Camilli, A. 1999. Regulation and temporal expression patterns of Vibrio cholerae virulence genes during infection. Cell, 99: 625-634.

Masters, C. I., Shallcross, J. A. and Mackey, B. M. 1994. Effect of stress treatments on the detection of Listeria monocytogenes and enterotoxigenic Escherichia coli by the polymerase chain reaction. J. Appl. Bacteriol., 77: 73-79.

McIngvale, S. C., Elhanafi, D. and Drake, M. A. 2002. Optimisation of reverse transcriptase PCR to detect viable shiga-toxinproducing Escherichia coli. Appl. Environ. Microbiol., 68: 799-806

Morin, N. J., Gong, Z. and Li, X. F. 2004. Reverse transcriptionmultiplex PCR assay for simultaneous detection of Escherichia coli O157, H7, Vibrio cholerae O1 and Salmonella Typhi. Clin. Chem., 50: 2037-2044.

Rivera, I. N. G., Chun, J., Huq, A., Sack, R. B. and Colwell, R. R. 2001. Genotypes associated with virulence in environmental isolates of Vibrio cholerae. Appl. Environ. Microbiol., 67: 2421-2429.

Sheridan, G. E. C., Masters, C. I., Shallcross, J. A. and Mackey, B. M. 1998. Detection of mRNA by reverse transcriptionPCR as an indicator of viability in Escherichia coli cells. Appl. Environ. Microbiol., 64: 1313-1318.

Shikongo-Nambabi, M. N. N. N., Petrus, N. P. and Schneider, M. B. 2012. The role, isolation and identification of Vibrio species on the quality and safety of seafood. Biotechnol. Mol. Biol. Rev., 7: 16-30.

Theron, J., Cilliers, J., Du Preez, M., Brozel, V. S. and Venter, S. N. 2000. Detection of toxigenic Vibrio cholerae from 
environmental water samples by enrichment broth cultivationpit-stop semi-nested PCR procedure. J. Appl. Microbiol., 89: 539-546.

Tolker-Nielsen, T., Larsen, M. H., Kyed, H. and Molin, S. 1997. Effects of stress treatments on the detection of Salmonella typhimurium by in-situ hybridisation. Int. J. Food Microbiol., 33: $251-258$
Wang, R. F., Cao, W. W. and Cerniglia, C. E. 1997. A universal protocol for PCR detection of 13 species of food borne pathogens in foods. J. Appl. Microbiol., 83: 727-736.

Yaron, S. and Matthews, K. R. 2002. A reverse transcriptasepolymerase chain reaction assay for detection of viable Escherichia coli O157, H7, investigation of specific target genes. J. Appl. Microbiol., 92: 633-640. 